\title{
Parameters of Attention at Work (PAW36)—Construction of a Questionnaire
}

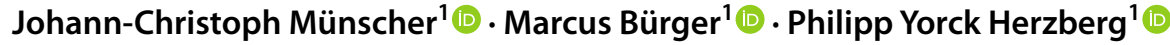

Accepted: 7 June 2021 / Published online: 4 August 2021

(c) The Author(s) 2021

\begin{abstract}
Assessing occupational demands of attention plays a vital role in job analysis which is mandatory to assess and optimize person-job fit. In this article, we aim to contribute to this field by presenting a novel questionnaire, Parameters of Attention at Work (PAW36). It is a German job analysis tool (a yet untested English translation is provided) that enables the differentiated assessment and interpretation of thoroughly derived task-oriented parameters (attentional job characteristics). A stepwise construction, using a pretesting sample $(N=268)$ followed by the main study with German adults $(N=800)$, and cross-validation resulted in a final version of 36 items loading on seven subscales that reflect task-oriented attentional demands at work. Initial validation efforts indicate that the PAW36 questionnaire is a useful and generally applicable assessment tool—e.g., in the field of job analysis or job design—both for practitioners and researchers.
\end{abstract}

Keywords Job analysis · Attention · Assessment · Questionnaire

The present article reports the construction process of a novel task analysis tool that provides information on task-oriented job characteristics (parameters) that constitute attentional demands. The German 36-item questionnaire is applicable in the fields of job analysis or job design, unfolding effectiveness through a comprehensive description of occupational demands of attention. An English translation of the questionnaire can be found in the supplemental materials.

In various disciplines, a range of theories and models of attention have emerged and were adapted to specific requirements. A widely accepted approach assumes that three networks of attention perform alerting, orientation, and conflict resolution

This study was preregistered with the OSF.io on August 1, 2019 (https://osf.io/dt8vr).

Johann-Christoph Münscher

J.Muenscher@hsu-hh.de

1 Personality Psychology and Psychological Assessment, Department of Psychology, Helmut

Schmidt University of the Federal Armed Forces, Hamburg, Germany 
(see Mahoney et al., 2010). These aspects are further separated into the theoretical dimensions alertness, sustained attention, vigilance, spatial attention, selective attention, focused attention, divided attention, and executive attention (Cohen, 2014; Goldhammer et al., 2007; Moosbrugger et al., 2006; Posner \& Boies, 1971; Posner \& DiGirolamo, 2000; Sturm, 2009). The advantage of a multidimensional perspective on attention is the applicability across various fields and domains. An example is, work-related fields such as occupational psychology, where the concept of person-job fit (PJ-fit) is central (Kristof-Brown et al., 2005). PJ-fit describes the degree to which occupational demands match employee resources and vice-versa. Implications are farreaching and they are especially relevant in occupations with intense responsibilities and demands (Bakker \& Demerouti, 2007). Assessing PJ-fit requires comparing the demands of a task with the degree to which an individual can meet the requirements of the domains physical, mental, emotional, and social (Edwards et al., 1991). Attention, as a mental demand, is frequently part of this procedure and a wide array of measures of attention has been developed to assess an individual's abilities (the person side of PJ-fit). Bakker and Demerouti (2007) point out the compensatory costs of excessive demands on attention and related faculties that can cause negative short and long-term detriments. Repeatedly, the importance of attention in the workplace has been investigated using high-demand occupations, for example, nurses and air traffic operators (Averty et al., 2004; Mohammadi et al., 2015).

Given the importance of attention and PJ-fit, we were surprised to find that the psychometric investigation of attention as an occupational demand (the job side of PJ-fit) is covered only by a small selection of instruments. Some of the current job analysis tools incorporate elements of attentional demands; however, few allow for a broad assessment of attentional demands at work; see Table 1 for a summary of selected measures. One such instrument is the Fleishman Job Analysis Survey (F-JAS) (Caughron et al., 2012); it is a prominent tool that provides a perspective on many constructs including a somewhat differentiated perspective on attention. Most other measures integrate attention in generalized constructs like psychological demands, stress, or the overarching concept of workload (MacDonald, 2003). Measures like the Normative and Subjective Assessment of Working Conditions (NUSA) (Riedel et al., 2005) or the Subjective Satisfaction and Strain by Work and Occupation Questionnaire (SZBAB) (Weyer et al., 2014) strive to provide a perspective on an individual's perception and experience at work. They include aspects of attentional demands but do not specifically address them. Other measures aim to broadly describe occupations, such as the Short Questionnaire for Job Analysis (KFZA) (Prümper et al., 1995) and the Work Design Questionnaire (WDQ) (Morgeson \& Humphrey, 2006). They both cover aspects of attentional demands in the form of, among others, taskvariety and cognitive demands, each with a low number of items. The specific demands on attention are not well represented within these instruments. Similarly, the Copenhagen Psychosocial Questionnaire (COPSOQ) (Nübling et al., 2006) aims to provide an overarching representation of an occupation that does not pursue an in-depth analysis of attentional demands. Some instruments, such as the Multiple Resources Questionnaire (MRQ) (Boles \& Adair, 2001), only include single dimensions like selective attention. Instruments dedicated to measuring an 


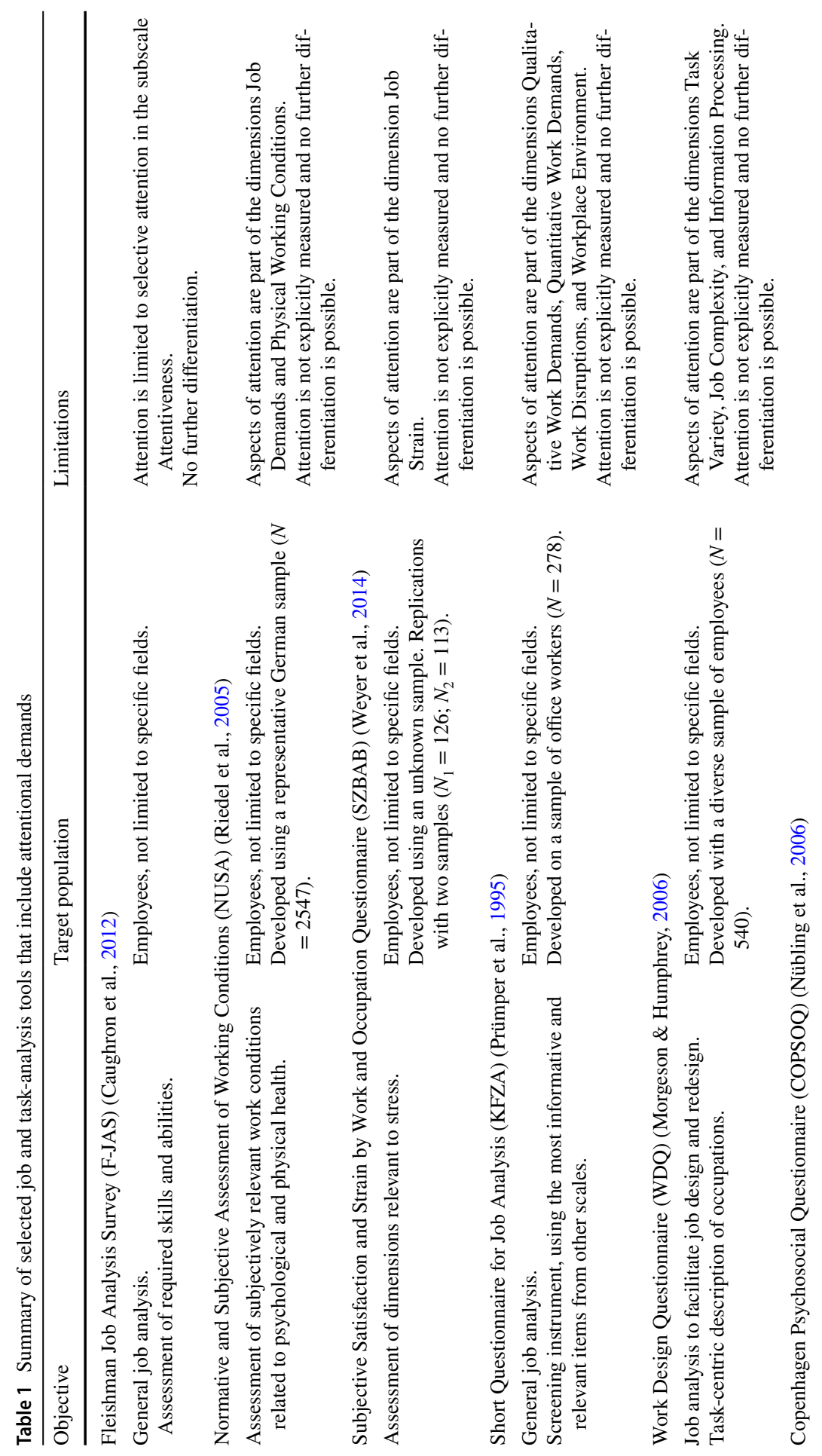




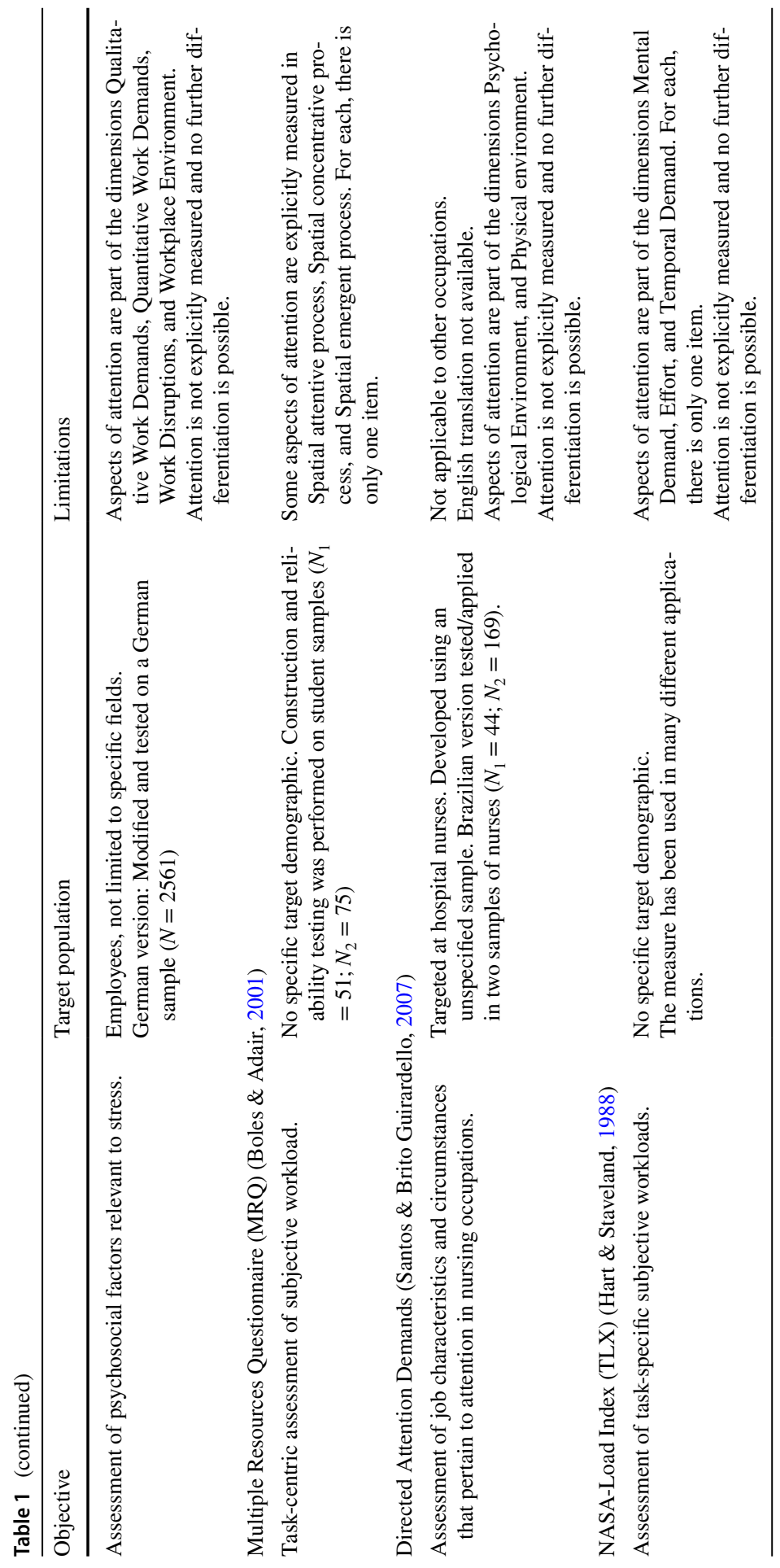


occupation's various demands on attention in a comprehensive and theory-driven manner are rare and often problematic. For instance, the questionnaire Directed Attention Demands aims to measure attentional demands on nurses (Santos \& Brito Guirardello, 2007); however, psychometric quality is lacking and an English translation for the Portuguese instrument is not available. A more popular but much less differentiated example is the NASA-Load Index (TLX); a short, taskoriented questionnaire that is used to measure the physical and mental load of a task (Hart \& Staveland, 1988).

In most measures, attention is either included as an element of a wider perspective (e.g., F-JAS) or is limited to one or a few aspects (e.g., MRQ). This observation partially echoes the sentiment by Morgeson et al. (2016), who conclude that job analysis is often performed holistically while a "decomposed" and theoretically driven perspective is more desirable. Thus, we elected to construct a measure that provides information on how attention is required in occupations based on the common dimensional theory of attention. We believe that an economical tool offering a comprehensive perspective on attentional demands is both useful and important. Creating differentiated requirement profiles for a range of occupations is beneficial for practical and research applications.

For the construction process, we proceeded in the three stages of scale construction, item development, scale development, and scale evaluation; Fig. 1 illustrates the process of construction (Boateng et al., 2018). First, reviewing theories of attention and identifying relevant parameters of occupations resulted in a framework of task parameters (step 1). Secondly, items were created to operationalize these parameters (step 2). Thirdly, the item pool was refined initially (step 3) and deployed in a cross-validation design, further refining the item pool using exploratory factor analysis (EFA, step 4) and validating the structure using confirmatory factor analysis (CFA, step 5) on separate samples. Comparisons with related measures (step 6) allowed for initial indications of validity. Finally, item selection resulted in a set of subscales that can be used to create an interpretable profile (step 7).

\section{Construction of the Parameters of Attention at Work}

As a multidimensional perspective on attention exhibits the aforementioned advantages, the initial goal was to construct items close to or based on the dimensions of attention. We began to construct items that aimed to directly operationalize the dimensions of attention. For example, by creating items pertaining to sustained attention such as "It is necessary to attend to things for a long time." During this process, the challenges of this approach became apparent as directly translating some of the dimensions of attention into job analysis items led to difficult and cumbersome wordings. This was primarily caused by the overlap between the dimensions such as sustained attention and vigilance. For example, the latter required nested aspects to capture vigilance and not sustained attention, such as "It is necessary to attend to a range of things for a long time with actions rarely being required." This also resulted in the need for very specific item wordings to express the differences between dimensions of attention that are similar yet theoretically separate (e.g., focused and 
Fig. 1 Overview of the present study illustrating the steps of scale development and validation (Boateng et al., 2018)
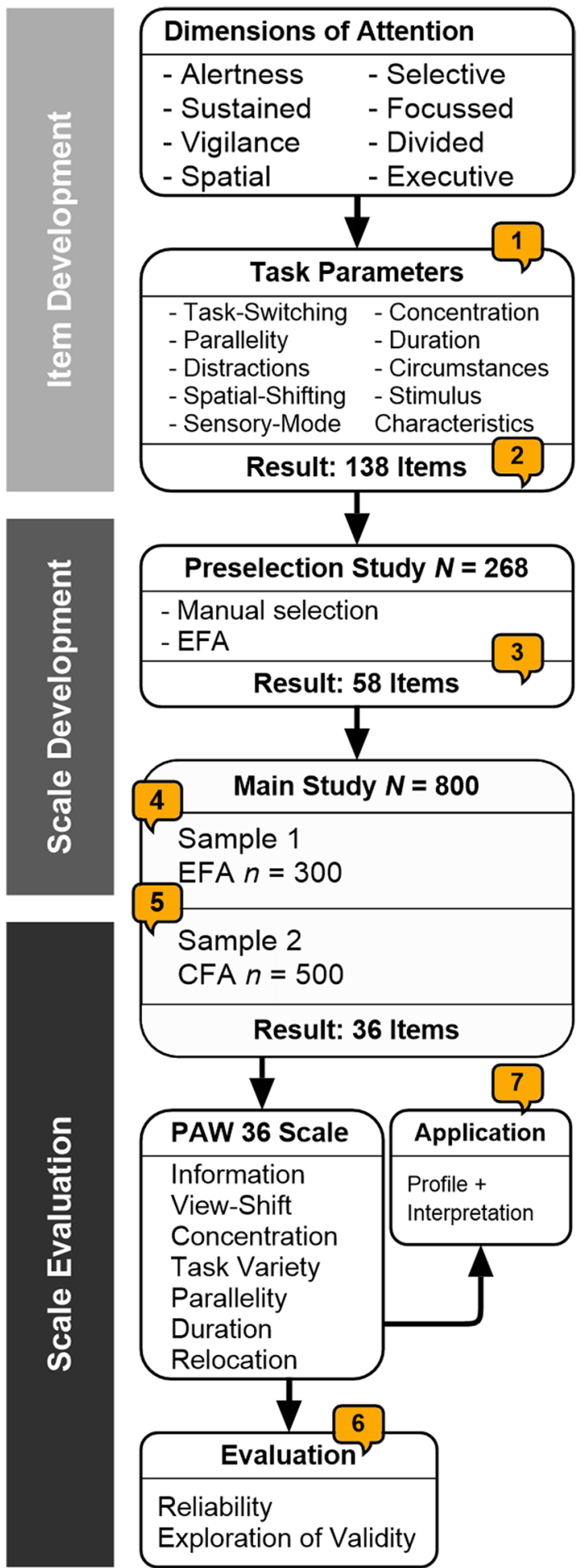

Sample 2

CFA $n=500$
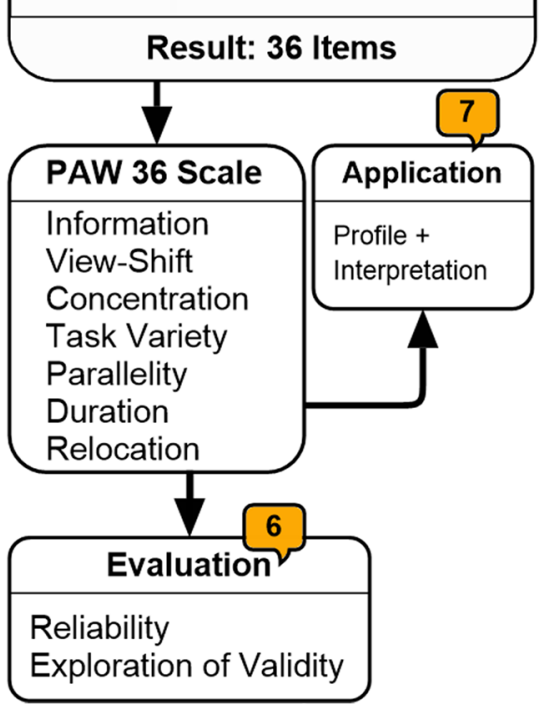
selective attention). Consequently, the decision was made to pursue a task-centric approach. Instead of measuring the dimensions of attention "directly," we first identified a framework of characteristic task parameters that correspond to the dimensions of attention. Masoudian and Razavi (2018) reported a similar approach and identified 11 parameters that describe aspects of tasks that constitute demands on vigilance in the workplace (for example, rate of Event, the frequency of relevant stimuli). As their approach was focused on vigilance only, we decided to expand on it to create a broader framework. The resulting scale seeks to measure the relevant parameters that correspond to these dimensions.

\section{The Task Parameters}

For this article, we define parameters as those aspects of occupations that are associated with demands on attention from a general perspective. The following section outlines which parameters were defined to operationalize them in a questionnaire to capture a task's characteristic configuration (Fig. 1, steps 1 \& 2). Table 2 provides an overview of the relations of dimensions of attention and the resulting questionnaire subscales.

Traditionally, switching between tasks is a common attentional requirement that primarily pertains to orientation and executive control. Demands increase with task competition and time constraints. Gilbert and Shallice (2002) concluded that these characteristic mixing costs are caused by states of activation and associations that carry over from the old task and interfere with the new. Masoudian and Razavi (2018) simplified this mechanism by identifying the parameter "successive tasks" as a relevant contributor to cognitive demands. Thus, we determined taskswitching as the first parameter; it requires switching attention between tasks, as well as avoiding interference between them. We also concluded that differentiating sub-parameters was necessary and determined that task-distance, denoting dissimilarity or competition between tasks is a relevant aspect. We additionally decided to include the number of different tasks, the number of switches in a given time, and time constraints when switching. These aspects modulate the degree to which carryover interferes with task performance; thus, the sub-parameters task-number, switching-frequency, and switching-speed were added. A relatively new concept in terms of task-switching is switching attention between internal and external information (Verschooren et al., 2019); characteristic switching costs have been observed when shifting between domains. However, we found that defining a separate task parameter reflecting this concept was not necessary as the underlying requirement for executive control was included in a dedicated parameter described later.

From the dimensional perspective on attention, task-switching primarily relies on selective, divided, and executive attention. Neuropsychological evidence suggests that splitting, selecting, and switching attention is processed in common neural areas (Hirsch et al., 2018) and cognitive demands seem to be similar (Hahn et al., 2008). Thus, divided attention is sometimes viewed as a variant of task-switching. However, from a task-centric perspective, the aspect of simultaneous performance is distinctly separate from serial task-switching. A distinction echoed by Krumm 
Table 2 Summary of task parameters and their relation to dimensions of attention and the resulting questionnaire sub-scales

\begin{tabular}{|c|c|c|c|c|c|c|c|c|}
\hline \multicolumn{8}{|c|}{ Dimensions of attention $^{a}$} & \multirow[t]{2}{*}{ PAW36 subscales } \\
\hline Parameters & SA & $\mathrm{V}$ & $\mathrm{SpA}$ & SelA & FA & $\mathrm{DA}$ & EA & \\
\hline \multicolumn{9}{|l|}{ Task-switch } \\
\hline Distance & & & & + & & + & & Task-variety \\
\hline (Number) & & & & + & & + & & \\
\hline Frequency & & & & + & & + & & \\
\hline Speed & & & & + & & + & & \\
\hline \multicolumn{9}{|l|}{ Stimulus } \\
\hline Density & + & - & & + & & + & & Information \\
\hline Relation & + & - & & + & & & & \\
\hline \multicolumn{9}{|l|}{ Spatial-shift } \\
\hline Distance & & & + & & & & & Relocation + view shift \\
\hline (Number) & & & + & & & & & \\
\hline Frequency & & & + & & & & & \\
\hline Speed & & & + & & & & & \\
\hline \multicolumn{9}{|l|}{ Control } \\
\hline Inhibition & & & & & + & & + & Control \\
\hline Selection & & & & + & + & & + & \\
\hline Control & & & & + & + & & + & \\
\hline Duration & + & + & & & & & & Duration \\
\hline Parallelity & & & & + & + & + & & Parallelity \\
\hline Distraction & & & & & + & + & & \\
\hline (Sensory mode) & & & & & & + & & \\
\hline Circumstances & & & & & & & & \\
\hline
\end{tabular}

${ }^{a}$ Abbreviated types of attention: $S A$ sustained attention, $V$ vigilance, $S p A$ spatial attention, SelA selective attention, $F A$ focussed attention, $D A$ divided attention, $E A$ executive attention

Elements in brackets were omitted in initial item construction

et al. (2012), who found that tests of attention employ either sequential or parallel tasks. Similar to "simultaneous tasks" defined by Masoudian and Razavi (2018), we identified parallelity (i.e., performing multiple tasks simultaneously) as a relevant parameter of tasks.

Another relevant parameter, related to divided attention and task-switching, is the need to manage distractions. It is especially relevant in the workplace (Tams et al., 2015), and managing distractions can be viewed as an interfering task. Therefore, we recognized distractions (i.e., actively ignoring distractions, interruptions, or intrusions) as a relevant parameter.

Much like splitting attention, spatially directing attention is closely related to orienting attention in general, yet it is treated as a separate dimension of attention. It is distinguished by a physical parameter - the distance between locations to attend to (Hamker, 2004) — which sets it apart from selective and split attention. From this observation, we derived the task parameter spatial-shifting. Following the structure 
in the parameter task-switching, we describe demands on spatial shifting with the four components: shifting-distance (distance between the locations); shifting-number (number of different locations); shifting-frequency (number of relocations in a given time); and shifting-speed (time constraints when relocating).

We approached differences in sensory mode during a task in a similar fashion, as changes in sensory mode are also associated with switching or integration costs when multisensory demands occur (Talsma et al., 2010). Masoudian and Razavi (2018) identified a pair of relevant parameters named "cognitive," and "sensory mode." Thus, we added the parameter sensory-switching (processing stimuli occupying multiple sensory channels) to the theoretical framework.

Metacognitive loads, specifically executive control, are primarily represented by the concept of executive attention, which is viewed as a separate dimension but is also associated with general aspects of orienting (Schweizer et al., 2005). In tasks, executive attention is characterized by the demand for higher-order cognitive processing manifested by, among others, the need for deliberated reactions, planning, careful selection of attentional targets, and reasoning. Hence, we derived the parameter control; it denotes requirements for executive attention, required by higher mental processing in later stages of perception. This workload includes the semantic complexity of tasks and their demand on working memory (Baddeley, 2010). Our control parameter closely matches "situation awareness," a parameter determined by Masoudian and Razavi (2018) which includes the perception and comprehension of stimuli, as well as the deduction of future outcomes. For the present framework, we specified the parameter control with the components, inhibition (controlling reactions), selection (deliberately selecting a response), and complexity (degree of planning and cognition).

Sustaining attention over a prolonged period is associated with cognitive demand (Esterman \& Rothlein, 2019). Over periods of performance, mental fatigue sets in, causing increases in errors and oversights. As the corresponding task parameter, we thus defined duration. We surmise that the demand to be attentive over time can be inherent to the task but can also be defined by the structural circumstances of a job. Shift length, for example, is a factor that influences demands without necessarily modifying the task itself. Such influences modify the amount of control an individual has over the structure of tasks. Krumm et al. (2012) identified the related concept "pace," which differentiates force-paced or self-paced tests of attention to be relevant in the context of test performance. Applying this argument to the workplace, we identified the degree to which a task is affected by circumstances as a related parameter.

Of note, within the parameters that have been laid out so far, a range of overarching aspects of tasks determine which dimension of attention is primarily required for completion. In differentiating sustained attention from vigilance, concerning corresponding task parameters, it became evident that task parameters alone were insufficient. Vigilance and sustained attention are both characterized by being attentive over an extended period; the distinction between them lies in the amount and type of stimuli that have to be processed. Sustained attention is characterized by processing relatively many, vigilance by relatively few relevant stimuli. Consequently, we recognized that characteristics of stimuli that have to be 
processed within tasks had to be included as well. Applying this line of thinking to vigilance, Masoudian and Razavi (2018) identified the parameters "rate of event" and "complexity" (the amount of information and its sources). We incorporated this approach more generally by defining the parameter stimulus characteristics with the two sub-parameters: density (overall number of stimuli) and relation (proportion of relevant to irrelevant stimuli).

In summary, based on theoretical deliberations and pertinent models of attention, we constructed a framework of 18 parameters and sub-parameters, some of which are grouped. In total, nine primary parameters of tasks were found to be relevant to attentional demands-task-switching, parallelity, distractions, spatialshifting, sensory-mode, concentration, duration, circumstances, and stimulus characteristics. The parameters were determined to reflect the characteristic differences between the aspects of the multidimensional perspective on attention. Assuming these parameters are sufficiently covering the different dimensions of attention, we presume that the original item pool generated from these items is content valid.

\section{Item Creation and Questionnaire Design}

For each parameter and sub-parameter, we created 10 pairs of short, opposing statements expressing core concepts. For example, two statements for task-distance were "perform different actions" and "do the same thing." From such statements, we created an initial item pool that was refined and deployed in a preselection study (the original item pool was created and applied in German; for clarity, we reference the English translation in the present article). We grouped the items by their underlying parameter and added short descriptions for each item group to aid understanding-i.e., "In everyday work, simple and complex actions are sometimes necessary. Evaluate how events usually need to be responded to." The items then completed the sentence "In my work activities..." and a 7-point Likert scale (does not apply - strongly applies) was used to gather responses. As an example, from the two statements above, the items "...very different actions and activities are carried out." and "...you usually have to do the same thing." were rated by respondents.

In the construction process, we realized that creating items for the parameter sensory mode resulted in long and overly complex items. This was also the case for items differentiating between the components frequency and number, both for spatial-shifting and task-switching. The sub-parameters sensory mode and number (spatial and task) were thus omitted during item construction and items pertaining to these parameters were not administered. Consequently, items were created for 15 of the 18 parameters, and the resulting pool was evaluated and optimized in the steps illustrated in Fig. 1. 


\section{Method}

The construction process presented in the present article was primarily based on the steps outlined by Boateng et al. (2018) and carried out in the three phases, item development, scale development, and scale evaluation. After item creation, the item pool was reduced by preselection and empirical testing in a preselection study followed by the main study. In both studies, we followed recommendations by Worthington and Whittaker (2006): first, we evaluated the sampling adequacy based on The Kaiser-Meyer-Olkin (KMO) criterium. Then, EFA was employed with oblique rotation as the resulting factors of attentional demands can be assumed to be correlated. In the main study, cross-validation using confirmatory factor analysis was employed to evaluate the extracted factors in their dimensionality and reliability before an initial assessment of validity.

\section{Preselection Study}

We used an initial preselection study to screen for problematic items and explore the factor structure of the item pool. Through manual preselection by experts (postgraduate members of the department), five items for each (sub-)parameter were selected based on wording, content, and clarity. In this procedure, we reduced the initial pool of 138 items to 75 and deployed the first version with an opportunity sample of employed individuals recruited by university students $\left(N_{\text {pre }}=268 ; 150\right.$ females (55\%); [20-79] years, $M=32$, SD=12). Exploratory factor analysis with ordinary least-squares extraction and Promax rotation (excellent sampling adequacy, KMO =0.91 (Dziuban \& Shirkey, 1974)) was used to explore the factor structure and exclude items with absolute main loadings $<0.5$. Afterward, a pool of 45 items resulted in a stable 6-factor solution. The theoretically assumed parameters of the framework were largely repeated in the factor structure, although with less differentiation. Interestingly, all items of the parameter circumstances had to be removed due to inadequate loadings. After the screening process, some factors had drastically fewer items associated with them; therefore, we created 13 new items to compensate. This procedure resulted in an item pool of 58 PAW items which we used in the main study.

\section{Main Study}

The main study further optimized the item selection for cross-validation using a sample of German adult incumbents of various fields. EFA using a randomly determined sub-sample was used to finalize the item selection by identifying a satisfactory factor solution. As before, each item was required to have one significant main loading and no substantial cross-loadings and each resulting factor had to contain at least three items. 


\section{Hypotheses and Expectations}

For the resulting scale, the following hypotheses were formulated:

Hypothesis 1: The measure is a factorially valid instrument for measuring attentional demands in the workplace based on confirmatory factor analysis [in CFA, requirements for adequate fit, based on common recommendations (Byrne, 2016; Hair, 2010), will be met: $\mathrm{C}_{\text {min }} / \mathrm{df}<3$; TLI, CFI $>0.9$; RMSEA < . 08]. ${ }^{1}$ The mentioned thresholds for fit indices were deliberately set to be somewhat lenient while still indicating adequate fit as the subject matter has not yet been explored similarly. Hypothesis 2: The measure is a reliable instrument for assessing attentional demands in the workplace [internal consistency for every dimension, $r>0.7$ ].

Expectations on nomological validity were based on the factor structure we found in the preselection sample. ${ }^{2}$ Three types of assumptions were made: no correlation $(r<0.3)$, correlation $(0.3 \leq r<0.6)$, and strong correlation $(r \geq 0.6)$ : no correlations exist between the final questionnaire scales and other scales pertaining to the degree of administrative control, social support, company benefits. Based on results presented by Morgeson and Humphrey (2006), we expect correlations between demand aspects and satisfaction with one's occupation. Accordingly, duration will likely show correlations with scales of demands and burnout. As distractions and stimuli from the environment are associated with processes of selection and executive control (Lavie et al., 2004), we expect corresponding correlations between switching and splitting of attention, as well as processing distractions, with scales of environmental circumstances, demands, disruptions, environmental influences, and stress. Furthermore, executive demands are assumed to correlate with scales of demands, burnout, and autonomy, and strongly correlate with qualitative demands. Prümper et al. (1995) describe the aspect of variability as a relevant task characteristic. Based on its theoretical overlap with the parameter task-variety, we expected correlations between taskvariety and scales of variability and demands.

\section{Main Sample}

The complete sample consisted of $N=800$ (373 female (47\%), 1 unknown; [19-82] years, $M=48, \mathrm{Mdn}=50, \mathrm{SD}=12$ ) adult individuals from Germany, who were or have been employed; please see Table 3 for sample details. In August of 2019, a commercial market research panel was used to recruit participants, who received monetary compensation; overall data from 926 respondents were collected. Due to low response quality (determined with two control questions) or incomplete data, 126 respondents were excluded. Alongside age and gender,

\footnotetext{
${ }^{1}$ In the preregistration, a wider range of fit indices was defined; to simplify the methods and results, the selection was reduced. The final evaluation remained unchanged.

${ }^{2}$ Initially, hypotheses were formulated in the OSF preregistration. After additional research and in light of the quality of the used scales, the decision was made to explore them as assumptions instead of testing them as hypotheses.
} 
Table 3 Sample description

\begin{tabular}{|c|c|c|c|c|c|}
\hline & Sample $N=800$ & $\begin{array}{l}\text { Male } \\
426\end{array}$ & $\begin{array}{l}\% \\
53\end{array}$ & $\begin{array}{l}\text { Female } \\
373\end{array}$ & $\begin{array}{l}\% \\
47\end{array}$ \\
\hline \multirow[t]{7}{*}{ Age } & $18-25$ & 8 & 1 & 8 & 1 \\
\hline & $26-29$ & 24 & 3 & 33 & 4 \\
\hline & $30-39$ & 71 & 9 & 71 & 9 \\
\hline & $40-49$ & 81 & 10 & 96 & 12 \\
\hline & $50-64$ & 201 & 25 & 143 & 18 \\
\hline & $65-74$ & 38 & 5 & 22 & 3 \\
\hline & $75+$ & 3 & $<1$ & 0 & 0 \\
\hline \multirow[t]{5}{*}{ Education } & Secondary education & 47 & 6 & 33 & 4 \\
\hline & Polytechnic secondary education & 35 & 4 & 23 & 3 \\
\hline & General Cert. of Sec. Education GCSE & 128 & 16 & 126 & 16 \\
\hline & General Cert. of Education GCE & 215 & 27 & 191 & 24 \\
\hline & Without certificate of education & 1 & $<1$ & 0 & 0 \\
\hline \multirow[t]{8}{*}{ Qualification } & Vocational training & 208 & 26 & 185 & 23 \\
\hline & Professional training & 59 & 7 & 46 & 6 \\
\hline & Higher technical qualification & 38 & 5 & 29 & 4 \\
\hline & College degree & 20 & 3 & 25 & 3 \\
\hline & Bachelors degree & 17 & 2 & 27 & 3 \\
\hline & Masters degree & 69 & 9 & 37 & 5 \\
\hline & $\mathrm{PhD}$ & 3 & $<1$ & 6 & 1 \\
\hline & Without degree & 7 & 1 & 12 & 2 \\
\hline \multirow[t]{10}{*}{ Area of occupation } & 1 Agriculture, farming & 2 & $<1$ & 6 & 1 \\
\hline & 2 Production, manufacturing & 88 & 11 & 26 & 3 \\
\hline & 3 Construction, architecture & 43 & 5 & 26 & 3 \\
\hline & 4 Natural sciences, informatics & 31 & 4 & 13 & 2 \\
\hline & 5 Logistics, security & 49 & 6 & 22 & 3 \\
\hline & 6 Trading, sales, tourism & 107 & 13 & 115 & 14 \\
\hline & 7 Accounting, law, administration & 44 & 6 & 50 & 6 \\
\hline & 8 Health care, teaching, education & 44 & 6 & 93 & 12 \\
\hline & 9 Humanities, social sciences, culture & 15 & 2 & 20 & 3 \\
\hline & 0 Armed forces & 3 & $<1$ & 2 & $<1$ \\
\hline
\end{tabular}

Note: Abbreviated titles for areas of occupation in KLDB 2010 (Dengler et al., 2014)

information on the highest education, level of qualification, employment status, area of occupation, and the number of years in this occupation were collected.

\section{Procedure}

Following the preselection, the main study was conducted in two stages. We employed a holdout cross-validation design (Koul et al., 2018) and randomly split the main 
sample into two subsamples $\left(n_{1}=300, n_{2}=500\right)$. The first was used to finalize the item selection using EFA; the second was used to validate this selection using CFA. Sample sizes were determined following recommendations by Guadagnoli and Velicer (1988), prioritizing the CFA step. Scores were calculated for scales of the final item selection alongside correlations with additional scales.

\section{Measures}

Alongside the PAW items, a selection of scales measuring related constructs was administered. Due to budgetary constraints, we employed a selection of freely available job and work-analysis measures: The Normative and Subjective Assessment of Working Conditions (NUSA) (Riedel et al., 2005) is a German job analysis questionnaire with 19 items. It contains the subscales job demands, job-decision-latitude, and physical working conditions; internal consistency lay between 0.72 and 0.78 . The KFZA-A Short Questionnaire for Job Analysis (Prümper et al., 1995) - comprises 26 German 5-point Likert rating items and was used to provide data on its eleven scales variability, completeness of task, job control, social support, cooperation, qualitative work demands, quantitative work demands, work disruptions, workplace environment, information and participation, and benefits. These subscales are grouped into the categories of job content, resources, stressors, and organizational culture. In the KFZA's initial construction, internal consistency for the scales ranged from 0.4 to 0.76 ; in a recent validation, values ranged from 0.63 to 0.8 (Appel et al., 2017). The KFZA was specifically selected because it contains many subscales that cover several concepts, many of which were used as indicators to explore convergent and discriminant validity. The SZBAB - Subjective Satisfaction and Strain by Work and Occupation-is a short questionnaire measuring job satisfaction and strain caused by work (Weyer et al., 2014). In total, 30 binary German items that fulfil the requirements of the Rasch-Model measure the three subscales job satisfaction, positive company climate, and job strain; reliability of the scales was estimated between 0.93 and 0.94 . In the present study, positive company climate was omitted in the interest of reducing the length of the survey. To finish, a subsection from the German short version of the Copenhagen Psychosocial Questionnaire was used (Nübling et al., 2006). Of the available scales in COPSOQ, quantitative demands, emotional demands, demands for hiding emotions, surroundings, and burnout were used. The selected scales utilize 5-point ratings; reported internal consistency ranged from 0.69 to 0.91 .

\section{Results}

Compared to the German adult population, age group 50-64 were overrepresented, as were holders of GCSE and GCE (German Realschule and Abitur) educations, while secondary education and holders of no qualification degree were underrepresented. In terms of occupational areas, group 6 (occupations in commercial services, trading, sales, the hotel business, and tourism) was overrepresented in the sample. Overall, $85 \%$ of the sample reported being employees, with the remainder being 
comprised of mostly self-employed (9\%) and marginally employed individuals (4\%). These differences in distribution are likely caused by the non-probabilistic nature of data acquisition in the market research panel. For statistical analysis, R Version 3.5.2 was used. EFA and CFA were performed using the packages psych and lavaan (Revelle \& Revelle, 2015; Rosseel et al., 2017); scripts and samples are accessible in the accompanying Open Science Framework repository (Foster \& Deardorff, 2017) (https://osf.io/8vrf7/?view_only=43cdacef05694a3ba08d7e5ca0df9608).

\section{Exploratory Factor Analysis}

EFA was performed on sample 1 , extracting seven factors $\left(n_{1}=300\right.$; excellent sampling adequacy, KMO=0.93 (Dziuban \& Shirkey, 1974)). As Likert-scale ratings are ordinal, weighted least-squares estimation for ordinal data (Barendse et al., $2015)$ and Promax $(\varkappa=4)$ rotation was employed. Although parallel analysis (Horn, 1965) suggested eight factors (see electronic supplemental material Fig. 1), based on the results gathered in the preselection study, we extracted seven factors as the eight-factor solution resulted in factors comprising only two items. As per the recommendations outlined by Hair (2010), only items with significant loadings (absolute main loading $>0.5$ ) and no cross-loadings (absolute difference between highest and second highest loading $<0.2$ and no secondary loading $>0.3$ ) were retained over multiple iterations of EFA. The final selection of Parameters of Attention at Work (PAW36) items resulted in a satisfactory solution (7 Eigenvalues $>1$ [1.27-12.48]; $64 \%$ explained variance), with an adequate fit $(\mathrm{RMSR}=0.022, \mathrm{RMSEA}=0.048$, Tucker-Lewis-Index $\left.=0.936, \chi_{300}^{2}=679.8, p<0.01\right)$. Factor correlations ranged from 0.04 to $0.66(M=0.36, \mathrm{SD}=0.17)$, loadings are reported in Table 4 , and factor correlations are reported in the electronic supplementary material. Commonalities for all items were greater 0.4 (Stinchcombe, 1971) except for item 33 (“...you have to stay focused despite boredom." $h^{2}=0.29$ ). Despite this suboptimal value, we did not exclude this item from the final selection to preserve its contribution to the factor.

\section{The PAW36 Questionnaire}

The final optimization step resulted in a questionnaire comprising 36 items, organized into seven subscales. As was the case in pretesting, the extracted factors reflected the theoretical categories. The theoretically assumed differentiation of 15 parameters was, however, not reflected in an equal number of factors. Table 4 displays the item numbers with relevant item characteristics in the complete sample (for full item wordings of the original German items as well as an English translation of the questionnaire, see electronic supplemental material). Based on factor composition and the theoretical assumptions underlying the items, the corresponding subscales were named: information, view-shift, concentration, task-variety, parallelity, duration, and relocation (for details on the theoretical composition of the factors, see Tables 2 and 3). 
Table 4 Factor composition and loadings

\begin{tabular}{|c|c|c|c|c|c|c|c|c|c|c|}
\hline \multirow[t]{2}{*}{ Factor } & \multirow[t]{2}{*}{$\alpha / \omega^{\mathrm{a}}$} & \multirow[t]{2}{*}{ Para. $^{\text {b }}$} & \multicolumn{7}{|c|}{ EFA factor loadings ${ }^{c}$} & \multirow[b]{2}{*}{$\mathrm{h}^{2}$} \\
\hline & & & 1 & 2 & 3 & 4 & 5 & 6 & 7 & \\
\hline Information & $.93 / .93$ & & & & & & & & & \\
\hline 1 & & S.D & .88 & .08 & .02 & .00 & -.01 & -.09 & .01 & .73 \\
\hline 2 & & S.D & .61 & -.15 & .15 & .12 & .06 & -.02 & .16 & .71 \\
\hline 3 & & S.D & .76 & -.07 & .08 & .06 & .02 & .07 & -.03 & .68 \\
\hline 4 & & S.D & .56 & -.04 & .04 & .07 & -.04 & .09 & .26 & .68 \\
\hline 5 & & S.R & .94 & .01 & -.04 & -.04 & -.04 & -.10 & -.06 & .67 \\
\hline 6 & & S.R & .92 & -.03 & -.06 & -.13 & .00 & -.02 & -.06 & .63 \\
\hline 7 & & S.R & .53 & -.09 & .07 & .09 & .11 & .13 & .17 & .69 \\
\hline 8 & & S.R & .86 & .03 & -.02 & .00 & -.01 & .00 & -.10 & .63 \\
\hline
\end{tabular}

View-Shift $\quad .86 / .85$

$\begin{array}{llllllllll}9^{\mathrm{r}} & \text { L.F } & -.06 & \mathbf{. 8 5} & .08 & .01 & .03 & -.06 & -.01 & .67 \\ 10^{\mathrm{r}} & \text { L.D } & -.09 & \mathbf{. 7 2} & .14 & .01 & -.01 & -.03 & -.06 & .47 \\ 11^{\mathrm{n}} & \text { L.D } & .14 & \mathbf{. 6 1} & -.21 & -.04 & -.03 & .22 & .13 & .75 \\ 12 & \text { L.D } & -.01 & \mathbf{. 5 2} & -.17 & .12 & -.05 & .29 & .02 & .64 \\ 13 & \text { L.F } & .11 & \mathbf{. 5 9} & -.22 & .05 & -.05 & .23 & .08 & .72\end{array}$

\section{Control}

$.82 / .82$

$\begin{array}{llllllllll}14^{\mathrm{r}} & \text { C.C } & .10 & .15 & \mathbf{. 6 9} & -.10 & .09 & -.08 & .12 & .6 \\ 15^{\mathrm{r}} & \text { C.C } & -.01 & -.01 & \mathbf{. 7 0} & -.01 & .00 & -.01 & .17 & .51 \\ 16^{\mathrm{r}} & \text { C.S } & -.05 & -.01 & \mathbf{. 8 1} & .08 & -.06 & .11 & -.11 & .62 \\ 17^{\mathrm{r}} & \text { C.S } & .06 & -.08 & \mathbf{. 7 0} & .03 & -.16 & .16 & -.12 & .46\end{array}$

Task-Variety $.93 / .92$

$\begin{array}{llllllllll}18 & \text { T.D } & .11 & .17 & -.03 & \mathbf{. 7 3} & -.02 & -.01 & -.14 & .61 \\ 19 & \text { T.D } & .08 & .05 & .01 & \mathbf{. 9 2} & -.04 & -.15 & -.03 & .77 \\ 20 & \text { T.F } & -.12 & -.02 & -.01 & \mathbf{. 8 9} & .04 & .02 & .01 & .73 \\ 21 & \text { T.F } & .09 & .10 & .00 & .77 & .06 & -.09 & -.08 & .65 \\ 22 & \text { T.F } & -.10 & -.14 & .04 & \mathbf{. 9 1} & .02 & .04 & .09 & .8 \\ 23 & \text { T.S } & -.07 & -.04 & .03 & \mathbf{. 7 6} & -.02 & .12 & .10 & .68\end{array}$

Parallelity $.84 / .84$

$\begin{array}{llllllllll}24 & \mathrm{P} & .14 & -.04 & -.04 & .06 & \mathbf{. 5 4} & .10 & .14 & .61 \\ 25 & \mathrm{P} & -.01 & -.03 & -.16 & .06 & \mathbf{. 9 8} & -.01 & -.09 & .83 \\ 26^{\mathrm{r}} & \mathrm{P} & -.11 & .20 & .30 & -.07 & \mathbf{. 5 6} & -.08 & -.03 & .45 \\ 27 & \mathrm{P} & .08 & -.14 & -.14 & .03 & \mathbf{. 8 7} & .12 & -.06 & .77\end{array}$

Relocation $\quad .85 / .85$

\begin{tabular}{|c|c|c|c|c|c|c|c|c|c|}
\hline 28 & & L.F & .06 & .05 & .12 & .00 & .01 & .65 & -.08 \\
\hline 29 & & L.D & -.02 & -.10 & .17 & -.02 & .01 & .88 & -.07 \\
\hline 30 & & L.S & -.16 & -.03 & -.03 & .04 & .05 & .66 & .08 \\
\hline 31 & & L.S & .03 & .07 & .02 & -.11 & .02 & .86 & -.06 \\
\hline 32 & & L.S & .02 & .18 & .00 & .00 & -.01 & .69 & .07 \\
\hline uration & $.75 / .75$ & & & & & & & & \\
\hline
\end{tabular}


Table 4 (continued)

\begin{tabular}{|c|c|c|c|c|c|c|c|c|c|c|}
\hline \multirow[t]{2}{*}{ Factor } & \multirow[t]{2}{*}{$\alpha / \omega^{\mathrm{a}}$} & \multirow[t]{2}{*}{ Para. $^{\text {b }}$} & \multicolumn{7}{|c|}{ EFA factor loadings ${ }^{c}$} & \multirow[b]{2}{*}{$\mathrm{h}^{2}$} \\
\hline & & & 1 & 2 & 3 & 4 & 5 & 6 & 7 & \\
\hline 33 & & $\mathrm{D}$ & -.03 & -.13 & -.19 & -.03 & -.05 & .06 & .55 & .29 \\
\hline 34 & & D & .02 & -.10 & .13 & .08 & .01 & -.01 & .81 & .74 \\
\hline 35 & & D & .04 & .16 & .12 & .02 & -.05 & -.16 & .87 & .77 \\
\hline 36 & & D & .05 & .16 & .05 & -.07 & -.03 & -.03 & .73 & .58 \\
\hline
\end{tabular}

Loadings from EFA $\left(n_{1}=300\right), \mathrm{h}^{2}$ denotes the item's commonality. Main loadings are highlighted in boldface

aStandardized Cronbach's alpha and total McDonald's omega calculated with the complete sample $(N=$ 800)

${ }^{\mathrm{b}}$ Corresponding parameters of the theoretical framework: (S.D, S.R) Stimulus Density \& Relation; (T.D, T.F, T.S) Task Distance, Frequency, \& Speed; (C.S, C.C) Executive Selection \& Complexity; (L.D, L.F) Location Distance \& Frequency; (D) Duration; (P) Parallelity

${ }^{\mathrm{r}}$ Reversed item

The first subscale, information $(M=5.73, \mathrm{SD}=1.06)$ describes the flow of data that needs to be processed and contains items from the task parameters stimulus-density and stimulus-relation. Higher values indicate that tasks and actions require a greater quantity of stimuli and information to be processed. Consequently, increased demand for selective attention and a higher potential for stress can be expected, as these two concepts correlate (Tams et al., 2015).

The second subscale, view-shift $(M=4.63, \mathrm{SD}=1.48)$, entails how often the field of view needs to be shifted, which requires refocusing of attention. The corresponding items originate from the parameters spatial-shift-distance and spatialshift-frequency. Higher values indicate that visual-spatial attention needs to be refocused frequently and to various locations.

The third subscale, concentration $(M=4.21, \mathrm{SD}=1.38)$, describes the complexity and cognitive demand of tasks. Items in this subscale stem from selection and control of the task-parameter concentration. Of note, all items of this scale are reverse coded, causing it to be a measure of simplicity. Higher values, therefore, indicate that substantial executive control is required and only a few actions are simple or repetitive. Control differs from information, in that it pertains to qualitative demands (top-down) of tasks rather than quantitative (bottom-up). Concentration primarily relates to executive attention and additionally encompasses aspects of selective and focused attention.

Task-variety $(M=5.04, \mathrm{SD}=1.38)$ comprises the number of different tasks and the frequency of switching between them. This fourth subscale contains items from the parameter task-switching; specifically, the sub-parameters task-distance and task-speed are represented in equal parts while task-frequency contributed one of the six items. Higher values in task-variety indicate that switching between tasks is a substantial part of a usual workday. Selective and divided attention is associated with task-variety, making task-variety a key subscale of workplace-related stress and mental strain.

Parallelity $(M=4.9, \mathrm{SD}=1.37)$ constitutes the fifth subscale, and expresses the degree to which tasks are performed simultaneously; higher values indicate that splitting one's 
attention to focus onto several things or working on a range of tasks at a time is routinely required. This subscale contains three items from the task-parameter of the same name and is characteristically associated with divided, focused, and selective attention.

The sixth subscale, relocation $(M=4.26, \mathrm{SD}=1.45)$, contains items constructed for location-speed, frequency, and distance, and pertains to the need to move oneself during a task. High values indicate that moving and relocation during the task at hand are required.

The seventh subscale, duration $(M=5.53, \mathrm{SD}=1.14)$, represents the degree to which tasks require prolonged attention; higher values indicate that attention has to be maintained for extended periods. Duration plays a vital role in constituting the demands for vigilance and sustained attention. Depending on how the dimension Information is expressed in a task with high duration, vigilance and sustained attention are more or less associated; low scores in information point towards vigilance, higher scores towards sustained attention.

All of the extracted subscales are comprised of items from one task parameter, no drifting of items occurred. Although the assumed separation of some parameters into sub-parameters did not occur, most of the parameters of the theoretical framework are represented. The complete instrument in German and English, as well as a scoring instruction, can be found in the electronic supplemental material.

Expression in the subscales can be evaluated in two ways. First, they can directly describe an occupation. Second, they can be interpreted to determine which dimensions of attention are required in an occupation. By using the associations between parameters and dimensions, displayed in Table 2, a differentiated description can be generated.

\section{Confirmatory Factor Analysis}

The factorial validity of the PAW36 was tested with CFA on sample $2\left(n_{2}=500\right)$. As neither single uni- nor multivariate normality was observable in the sample, robust maximum-likelihood estimation was used (Beauducel \& Herzberg, 2006; Rhemtulla et al., 2012). The $\chi^{2}$-test was significant with $\chi_{573}^{2}=1327.69(p<0.01)$, which is to be expected as this criterion is sensitive to sample size. The determined measures of goodness-of-fit (their robust variants) indicated acceptable fit as defined beforehand: standardized root mean residual $(\mathrm{SRMR}=0.054)$; root mean square of approximation (RMSEA $=0.051$ [90\%CI 0.048 - 0.055]); comparative fit index $(\mathrm{CFI}=0.921)$; and Tucker-Lewis index $(\mathrm{TLI}=0.913)$. A second-order model was calculated to test the viability of calculating a total score; decreases in fit below the specified thresholds indicate that determining a total score is not appropriate $(\mathrm{SRMR}=0.082, \mathrm{RMSEA}=0.065$ [90\%CI 0.062-0.068], $\mathrm{CFI}=0.896, \mathrm{TLI}=0.881)$.

\section{Internal Consistency, Scale Correlations, and Exploration of Nomological Validity}

Standardized internal consistency for the subscales ranged from Cronbach's $\alpha=0.79$ to 0.94 , with a composite score of $\alpha=0.93$. McDonald's omega ranged from $\omega=0.75$ to $\omega=0.93$, with a composite score of $\omega=0.96$. Overall, skewness ranged from -1.27 to $0.2[M=-0.6, \mathrm{SD}=0.4]$, and kurtosis from -1.1 to 1.52 
$[M=-0.18, \mathrm{SD}=0.81]$ (see Table 5 for details). Empirical scale correlations ranged from 0.04 to $0.66[M=0.36, \mathrm{SD}=0.17]$. Corrected item-scale correlations ranged from 0.35 to $0.82[M=0.69, \mathrm{SD}=0.09]$ and are reported in detail in the electronic supplementary material alongside all scale correlations and corrected itemtotal correlations.

Mean scores for the PAW36 subscales were correlated with the scale averages of KFZA, NUSA, SZBAB, and COPSOQ and ranged from -0.19 to $0.58[M=0.2$, $\mathrm{SD}=0.13$ ] (see Table 5). Additionally, preliminary analyses of measurement invariance with regards to age, gender, and occupational field indicate that no measurement variance was observed (results can be found in the supplemental materials).

Table 5 Convergent and discriminant correlations

\begin{tabular}{|c|c|c|c|c|c|c|c|c|c|}
\hline & \multirow[t]{2}{*}{ Subscale } & \multirow[b]{2}{*}{$\alpha^{\mathrm{a}}$} & \multicolumn{7}{|c|}{ PAW36 $^{\mathrm{b}}$} \\
\hline & & & $I$ & VS & $C$ & TV & $P$ & $R$ & $D$ \\
\hline \multirow[t]{6}{*}{ COPSOQ } & Quant. demands & .82 & .28 & .19 & .07 & .32 & .32 & .29 & .29 \\
\hline & Emot. demands & .64 & .31 & .27 & .22 & .36 & .35 & .39 & .23 \\
\hline & Hide emotions & .82 & .18 & .16 & .04 & .17 & .18 & .25 & .21 \\
\hline & Total demands & .81 & .34 & .27 & .15 & .37 & .38 & .4 & .32 \\
\hline & Burnout & .81 & .2 & .2 & .03 & .23 & .25 & .25 & .23 \\
\hline & Environment & .84 & .12 & .41 & -.12 & .19 & .23 & .32 & .2 \\
\hline \multirow[t]{11}{*}{ KFZA } & Job control & .77 & .11 & -.04 & .18 & .16 & .1 & -.01 & -.06 \\
\hline & Variablility & .38 & .55 & .2 & .43 & .59 & .42 & .31 & .3 \\
\hline & Completeness & .59 & .25 & .1 & .04 & .18 & .15 & .13 & .18 \\
\hline & Social support & .64 & .06 & .01 & .02 & .06 & .04 & -.04 & .05 \\
\hline & Cooperation & .58 & .24 & .05 & .11 & .25 & .26 & .13 & .17 \\
\hline & Qualitative dem & .76 & .28 & .03 & .09 & .23 & .21 & .24 & .22 \\
\hline & Quantitative dem & .77 & .36 & .24 & .1 & .37 & .4 & .35 & .35 \\
\hline & Disruptions & .58 & .18 & .13 & 0 & .34 & .3 & .33 & .18 \\
\hline & Environment & .50 & .09 & .18 & -.1 & .14 & .17 & .23 & .14 \\
\hline & Information & .84 & .09 & -.01 & .08 & .14 & .08 & 0 & .04 \\
\hline & Benefits & .85 & .15 & .03 & .18 & .2 & .16 & .12 & .09 \\
\hline \multirow[t]{3}{*}{ NUSA } & Demand & .80 & .38 & .29 & .24 & .41 & .43 & .36 & .36 \\
\hline & Decision latitude & .81 & .36 & .2 & .36 & .34 & .32 & .22 & .21 \\
\hline & Phys. cond & 79 & .03 & .5 & -.2 & .16 & .13 & .36 & .06 \\
\hline \multirow[t]{2}{*}{ SZBAB } & Satisfaction & .89 & .11 & .07 & .19 & .17 & .13 & .06 & 0 \\
\hline & Demand & .88 & .27 & .23 & .06 & .31 & .3 & .33 & .26 \\
\hline
\end{tabular}

Correlations were calculated with the completesample $(N=800)$, absolute values $>0.07$ are statistically significant at $\alpha=.05$

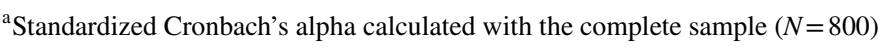

${ }^{\mathrm{b}}$ Abbreviated PAW36 sub-scales: $I$ information, $V S$ view-shift, $C$ concentration, $T V$ task-variety, $P$ parallelity, $R$ relocation, and $D$ duration

Absolute correlations $>.3$ are highlighted in boldface 


\section{Discussion}

Based on multidimensional theories of attention (Cohen, 2014; Goldhammer et al., 2007; Mahoney et al., 2010; Moosbrugger et al., 2006; Posner \& Boies, 1971; Posner \& DiGirolamo, 2000; Sturm, 2009), a framework of relevant task parameters was laid out and used for item creation. Item selection resulted in a questionnaire comprising 36 items associated with seven dimensions of task characteristics. Given the results of the cross-validation using EFA and CFA, the factorial validity of the instrument can be assumed.

Overall, the findings provide evidence of the nomological validity of the PAW36; both reasonable convergence and discrimination between constructs were observed. In line with the initial expectations, the KFZA scales job-control, completeness, cooperation, social-support, information, and benefits showed no substantial associations with PAW36 subscales. Scale definitions laid out by Prümper et al. (1995) indicate that these facets pertain to aspects related to company culture, leadership, and social interactions within the workspace and not to the performed tasks. Observing no meaningful association with the PAW36 subscales is thus an indication of discriminant validity. For KFZA-qualitative-demands, no meaningful associations to PAW36 scales were observed, which contradicts previous assumptions as this scale explicitly pertains to subjectively excessive cognitive demands in the form of concentration, information processing, and working memory. In this instance, associations with the PAW36 scales information, concentration, task-variety, and parallelity would have been in line with prior expectations. The KFZA-qualitativedemands items, however, specifically ask for demands that are perceived to be too high, whereas the PAW36 aims to measure the general magnitude of demands. This difference in intention may explain the lack of association in this case. Additionally, no association was observed with KFZA-environment (the demands and stress induced by environmental influences like dust and heat) and PAW36 scales concentration and parallelity. Distracting environmental influences are relevant to attention, especially in the workplace (Lavie et al., 2004; Tams et al., 2015) and an association would have matched the expectation.

Convergence was observed between some of the PAW36 subscales and the remaining KFZA scales. KFZA-variability (the number of different tasks and requirements) showed meaningful associations with all PAW36 scales, except view-shift. Especially the link to task-variety is noteworthy in this case. KFZAquantitative demands (the volume of work and time pressure) showed associations with PAW36 scales information, task-variety, parallelity, relocation, and duration. These links match the prior assumptions and indicate convergent validity.

As expected, PAW36-information and task-variety were associated with the demand scales in NUSA and COPSOQ. While both instruments seek to measure demands, they differ in their approach (Nübling et al., 2006; Riedel et al., 2005). NUSA collects data on the subjective evaluation while COPSOQ assesses the frequencies with which demands occur. Agreement between these two instruments and PAW36 scales thus indicates convergence on the same construct from slightly different perspectives. 
Assumptions for associations of PAW36 scales with SZBAB-satisfaction and COPSOQ-burnout could not be confirmed. While small associations between COPSOQ-burnout and PAW36-task-variety, parallelity, relocation, and duration correlations were observed, they did not exceed the defined threshold. As the PAW36 does not specifically target burnout or job (dis)satisfaction, this result might not be surprising. However, given the effects of fatigue and stress associated with attention demands and the link between task characteristics and job satisfaction described in the literature (Bakker \& Demerouti, 2007; Morgeson \& Humphrey, 2006), a more pronounced association was expected.

PAW36-parallelity exhibited associations with the majority of scales of demands from COPSOQ, KFZA, SZBAB, and NUSA, mostly matching the expectations. For the association with KFZA-disruptions however, the observed degree of convergence did not match the expectations. PAW36-duration showed substantial correlations with demand scales from all four instruments. Both PAW36-parallelity and duration thus appear as relevant aspects of demands which indicates convergent validity. Expectations for PAW36-control were only partly confirmed; KFZA-variability and NUSA-decision latitude showed relevant associations, whereas no link to burnout and qualitative demands was observed. PAW36-view-shifting showed expected correlations with COPSOQ-environment and NUSA-physical-condition; the correlation with NUSA-demand did manifest, but not to the assumed degree.

The underlying framework of originally determined task parameters was largely reflected in the scales of the PAW36. This observation supports the validity of the parameter framework and indicates that the measure represents it adequately. Of note, the assumed content validity of the initial item pool does not necessarily extend to the final item selection. Some of the aspects that were laid out in the framework of task parameters are not represented in the final instrument. For example, the aspect of circumstances, capturing influences outside a given task that may modulate the demand, did not transition to the final instrument. Likely, this is a result of respondents assessing the demands of tasks somewhat holistically, instead of differentiating task demands from circumstances. Consequently, the final item selection cannot be assumed to be content valid from a theoretical perspective. We assume the item selection represents those aspects that are content valid from an empirical perspective.

In summary, the PAW36 scales are associated with many aspects of demands overall. Nevertheless, the scales exhibit differentiated patterns of association that indicate each is a relevant contributor to the profile of attention demands. We, therefore, conclude that the construction of the PAW36 was successful; the resulting scores of the seven subscales can be used to describe an occupation's pattern parameters. The pattern can then be used to infer which dimensions of attention are predominantly required in an occupation. We believe that the described complications in creating items we initially encountered resulted in a beneficial outcome. Describing an occupation's attentional demands by detailing the parameters of said demands is much more tangible than using dimensions of attention exclusively. Additionally, a dimensional assessment can be derived from the parameters. Such information can be used in multiple ways such as job design, job description, optimizing and assessing PJ-Fit, burnout prevention, and research. 


\section{Contribution}

The present article provides two crucial contributions. The primary contribution is the job analysis tool that can be used in practice and research applications. It not only provides information on attentional demands for inclusion in general job profiles nomothetic but also enables an assessment of an individual's perception of a job idiographic. The measure is short yet reliable and therefore economical and thus extends the range of available job analysis tools. Its general utility can aid in determining and optimizing PJ-fit across a wide range of occupations and fields (Kristof-Brown et al., 2005). The PAW36 provides an approach to job analysis that cannot be fulfilled by any other similar tool in the field. Specifically highlighting attention as a mental domain (Edwards et al., 1991) and its decomposed determinants in the workplace can aid substantially in assessing and optimizing PJ-fit. Besides these practical implications, we believe that the selection of parameters constitutes the second relevant contribution. It provides a novel perspective on demands on attention and extends the perspective on vigilance by Masoudian and Razavi (2018) to attention in general. It allows a pragmatic and theory-driven approach that integrates well with multidimensional theories of attention. The questionnaire can easily be applied and answers the need for a decomposed and theory-driven perspective on attention (Morgeson et al., 2016).

\section{Limitations}

The selection of measures used to explore nomological validity in this study is an issue for improvement. Future applications should employ commonly used job analysis instruments - e.g., F-JAS (Caughron et al., 2012) - to assess the relationships that could only be explored thus far. Out of the initially constructed framework of parameters, some were not represented in the final questionnaire scales. On the one hand, this indicates that the excluded aspects were not as relevant, while on the other hand, it indicates that aspects that were deemed to be relevant from a theoretical perspective are not measured. Furthermore, no evaluation of criterion or prognostic validity of the final scales was performed; such deliberations are, however, vital from an application standpoint. Assessing PAW36 scores in the context of external criteria such as individual cognitive performance, and outcome variables associated with attention demands should be addressed. An individual's perception of their workplace and quantitative job performance should be of interest in this regard.

\section{Conclusions}

The present paper describes the construction of a novel job analysis questionnaire. We followed the usual design criteria throughout and conducted our study steps in line with current scientific state-of-the-art principles (i.e., the study is preregistered, theory-based, and hypothesis-driven, where possible). The central idea of strict adherence to the pertinent theoretical basement was continuously considered and maintained throughout the whole questionnaire construction process (please see 
Fig. 1 for an overview of the several steps taken). The final factor structure broadly reflects the initial parameters and represents those aspects of the theoretical framework that have shown empirical relevance. Therefore, the measure can provide comprehensive information on the composition of relevant attentional demands at work. Future research is needed to strengthen the first empirical evidence presented here, but our findings support the notion of PAW36 being a reliable and valid measure of attentional demands in the workplace.

Supplementary Information The online version contains supplementary material available at https://doi. org/10.1007/s43076-021-00086-y.

Funding Open Access funding enabled and organized by Projekt DEAL.

Data Availability The datasets generated during and/or analyzed during the current study are available in the OSF repository, [https://osf.io/8vrf7].

\section{Declarations}

Ethics Approval All procedures followed were in accordance with the ethical standards of the responsible committee on human experimentation (institutional and national) and with the Helsinki Declaration of 1975 , as revised in 2000. As this study included only adult participants without collecting personal information that could enable the identification of individuals, no approval by an ethics board was pursued.

Informed Consent Informed consent was obtained from all individual participants included in the study.

Competing Interests The authors declare no competing interests.

Open Access This article is licensed under a Creative Commons Attribution 4.0 International License, which permits use, sharing, adaptation, distribution and reproduction in any medium or format, as long as you give appropriate credit to the original author(s) and the source, provide a link to the Creative Commons licence, and indicate if changes were made. The images or other third party material in this article are included in the article's Creative Commons licence, unless indicated otherwise in a credit line to the material. If material is not included in the article's Creative Commons licence and your intended use is not permitted by statutory regulation or exceeds the permitted use, you will need to obtain permission directly from the copyright holder. To view a copy of this licence, visit http://creativecommons.org/licen ses/by/4.0\%.

\section{References}

Appel, P., Schuler, M., Vogel, H., Oezelsel, A., \& Faller, H. (2017). Short Questionnaire for Workplace Analysis (KFZA): Factorial validation in physicians and nurses working in hospital settings. Journal of Occupational Medicine and Toxicology (London, England), 12, 11. https://doi.org/10.1186/ s12995-017-0157-6

Averty, P., Collet, C., Dittmar, A., Athènes, S., \& Vernet-Maury, E. (2004). Mental workload in air traffic control: An index constructed from field tests. Aviation, Space, and Environmental Medicine, 75(4), 333-341.

Baddeley, A. (2010). Working Memory. Current Biology: CB, 20(4), R136-R140. https://doi.org/10. 1016/j.cub.2009.12.014

Bakker, A. B., \& Demerouti, E. (2007). The Job Demands-Resources model: State of the art. Journal of Managerial Psychology, 22(3), 309-328. https://doi.org/10.1108/02683940710733115 
Barendse, M. T., Oort, F. J., \& Timmerman, M. E. (2015). Using exploratory factor analysis to determine the dimensionality of discrete responses. Structural Equation Modeling: A Multidisciplinary Journal, 22(1), 87-101. https://doi.org/10.1080/10705511.2014.934850

Beauducel, A., \& Herzberg, P. Y. (2006). On the performance of maximum likelihood versus means and variance adjusted weighted least squares estimation in CFA. Structural Equation Modeling: A Multidisciplinary Journal, 13(2), 186-203. https://doi.org/10.1207/s15328007sem1302_2

Boateng, G. O., Neilands, T. B., Frongillo, E. A., Melgar-Quiñonez, H. R., \& Young, S. L. (2018). Best practices for developing and validating scales for health, social, and behavioral research: A primer. Frontiers in Public Health, 6, 149. https://doi.org/10.3389/fpubh.2018.00149

Boles, D. B., \& Adair, L. P. (2001). The Multiple Resources Questionnaire (MRQ). Proceedings of the Human Factors and Ergonomics Society Annual Meeting, 45(25), 1790-1794. https://doi.org/10. $1177 / 154193120104502507$

Byrne, B. M. (2016). Structural Equation Modeling With AMOS: Basic Concepts, Applications, and Programming, Third Edition (3rd ed.). Taylor and Francis.

Caughron, J. J., Mumford, M. D., \& Fleishman, E. A. (2012). The Fleishman Job Analysis survey: Development, validation, and applications. In Series in applied psychology. The handbook of work analysis: Methods, systems, applications and science of work measurement in organizations (pp. 231246). Routledge/Taylor \& Francis Group.

Cohen, R. A. (2014). The Neuropsychology of Attention ( $2^{\text {nd }}$ ed. 2014). Critical Issues in Neuropsychology. Springer US. https://doi.org/10.1007/978-0-387-72639-7

Dengler, K., Matthes, B., \& Paulus, W. (2014). Occupational Tasks in the German Labour Market: an alternative measurement on the basis of an expert database. FDZ Methodenreport (201412_en). Institut für Arbeitsmarkt- und Berufsforschung (IAB), Nürnberg [Institute for Employment Research, Nuremberg, Germany]. https://EconPapers.repec.org/RePEc:iab:iabfme:201412_en. Accessed 28 Sept 2019

Dziuban, C. D., \& Shirkey, E. C. (1974). When is a correlation matrix appropriate for factor analysis? Some Decision Rules. Psychological Bulletin, 81(6), 358-361. https://doi.org/10.1037/h0036316

Edwards, JR, Cooper, C. L., \& Robertson, I. T. (1991). International review of industrial and organizational psychology. Person Jop Fit: A Conceptual Integration, Literature Review, and Methodological Critique.

Esterman, M., \& Rothlein, D. (2019). Models of sustained attention. Current Opinion in Psychology, 29, 174-180. https://doi.org/10.1016/j.copsyc.2019.03.005

Foster, M. E. D., \& Deardorff, M. A. (2017). Open Science Framework (OSF). Journal of the Medical Library Association: JMLA, 105(2), 203-206. https://doi.org/10.5195/jmla.2017.88

Gilbert, S. J., \& Shallice, T. (2002). Task switching: A PDP model. Cognitive Psychology, 44(3), 297337. https://doi.org/10.1006/cogp.2001.0770

Goldhammer, F., Moosbrugger, H., \& Schweizer, K. (2007). On the separability of cognitive abilities related to Posner's attention components. European Psychologist, 12(2), 103-118. https://doi.org/ 10.1027/1016-9040.12.2.103

Guadagnoli, E., \& Velicer, W. F. (1988). Relation of sample size to the stability of component patterns. Psychological Bulletin, 103(2), 265-275. https://doi.org/10.1037/0033-2909.103.2.265

Hahn, B., Wolkenberg, F. A., Ross, T. J., Myers, C. S., Heishman, S. J., Stein, D. J., Kurup, P. K., \& Stein, E. A. (2008). Divided versus selective attention: Evidence for common processing mechanisms. Brain Research, 1215, 137-146. https://doi.org/10.1016/j.brainres.2008.03.058

Hair, J. F. (2010). Multivariate data analysis (7. ed.). Pearson Prentice Hall.

Hamker, F. H. (2004). A dynamic model of how feature cues guide spatial attention. Vision Research, 44(5), 501-521. https://doi.org/10.1016/j.visres.2003.09.033

Hart, S. G., \& Staveland, L. E. (1988). Development of NASA-TLX (Task Load Index): Results of empirical and theoretical research. In Advances in psychology (Vol. 52, pp. 139-183). Elsevier.

Hirsch, P., Nolden, S., Declerck, M., \& Koch, I. (2018). Common cognitive control processes underlying performance in task-switching and dual-task contexts. Advances in Cognitive Psychology, 14(3), 62-74. https://doi.org/10.5709/acp-0239-y

Horn, J. L. (1965). A rationale and test for the number of factors in factor analysis. Psychometrika, 30, $179-185$.

Koul, A., Becchio, C., \& Cavallo, A. (2018). Cross-validation approaches for replicability in psychology. Frontiers in Psychology, 9, 1117. https://doi.org/10.3389/fpsyg.2018.01117 
Kristof-Brown, A. L., Zimmerman, R. D., \& Johnson, E. C. (2005). Consequences of individuals' fit at work: A meta-analysis of person-job, person-organization, person-group, and person-supervisor fit. Personnel Psychology, 58(2), 281-342. https://doi.org/10.1111/j.1744-6570.2005.00672.x

Krumm, S., Schmidt-Atzert, L., Schmidt, S., Zenses, E.-M., \& Stenzel, N. (2012). Attention tests in different stimulus presentation modes. Journal of Individual Differences, 33(3), 146-159. https://doi. org/10.1027/1614-0001/a000085

Lavie, N., Hirst, A., de Fockert, J. W., \& Viding, E. (2004). Load theory of selective attention and cognitive control. Journal of Experimental Psychology. General, 133(3), 339-354. https://doi.org/10. 1037/0096-3445.133.3.339

MacDonald, W. (2003). The impact of job demands and workload on stress and fatigue. Australian Psychologist, 38(2), 102-117. https://doi.org/10.1080/00050060310001707107

Mahoney, J. R., Verghese, J., Goldin, Y., Lipton, R., \& Holtzer, R. (2010). Alerting, orienting, and executive attention in older adults. Journal of the International Neuropsychological Society: JINS, 16(5), 877-889. https://doi.org/10.1017/S1355617710000767

Masoudian, M., \& Razavi, H. (2018). An investigation of the required vigilance for different occupations. Safety Science. Advance online publication. https://doi.org/10.1016/j.ssci.2018.02.029

Mohammadi, M., Mazloumi, A., Kazemi, Z., \& Zeraati, H. (2015). Evaluation of mental workload among ICU ward's nurses. Health Promotion Perspectives, 5(4), 280-287. https://doi.org/10.15171/ hpp. 2015.033

Moosbrugger, H., Goldhammer, F., \& Schweizer, K. (2006). Latent factors underlying individual differences in attention measures. European Journal of Psychological Assessment, 22(3), 177-188. https://doi.org/10.1027/1015-5759.22.3.177

Morgeson, F. P., \& Humphrey, S. E. (2006). The Work Design Questionnaire (WDQ): Developing and validating a comprehensive measure for assessing job design and the nature of work. The Journal of Applied Psychology, 91(6), 1321-1339. https://doi.org/10.1037/0021-9010.91.6.1321

Morgeson, F. P., Spitzmuller, M., Garza, A. S., \& CAMPION, M. A. . (2016). Pay attention! The liabilities of respondent experience and carelessness when making job analysis judgments. Journal of Management, 42(7), 1904-1933. https://doi.org/10.1177/0149206314522298

Nübling, M., Stößel, U., \& Hasselhorn, H.-M. (2006). Measuring psychological stress and strain at work: Evaluation of the COPSOQ Questionnaire in Germany. Psycho-Social-Medicine(3).

Posner, M. I., \& Boies, S. J. (1971). Components of attention. Psychological Review, 78(5), 391-408. https://doi.org/10.1037/h0031333

Posner, M. I., \& DiGirolamo, G. J. (2000). Executive attention: Conflict, target detection, and cognitive control. In R. Parasuraman (Ed.), The attentive brain (pp. 401-425). Mit Press.

Prümper, J., Hartmannsgruber, K., \& Frese, M. (1995). KFZA - Kurzfragebogen zur Arbeitsanalyse [Short Questionnaire for Workplace Analysis (KFZA)]. Zeitschrift Für Arbeits- Und Organisationspsychologie(39), 125-132.

Revelle, W., \& Revelle, M. W. (2015). Package 'psych'. The Comprehensive R Archive Network.

Rhemtulla, M., Brosseau-Liard, P. É., \& Savalei, V. (2012). When can categorical variables be treated as continuous? A comparison of robust continuous and categorical SEM estimation methods under suboptimal conditions. Psychological Methods, 17(3), 354-373. https://doi.org/10.1037/a0029315

Riedel, J., Meyer, C., Rumpf, H.-J., John, U., \& Hapke, U. (2005). Die Normative und Subjektive Arbeitsanalyse (NUSA) [The normative and subjective assessment of working conditions (NUSA)]. Zeitschrift Für Arbeits- Und Organisationspsychologie a\&o, 49(3), 131-139. https://doi.org/10. 1026/0932-4089.49.3.131

Rosseel, Y., Oberski, D., Byrnes, J., Vanbrabant, L., Savalei, V., Merkle, E., Hallquist, M., Rhemtulla, M., Katsikatsou, M., \& Barendse, M. (2017). Package 'lavaan'. Retrieved June, 17, 2017.

Santos, L. S. C., \& de Brito Guirardello, E. (2007). Nurses' attention demands in the work setting. Revista Latino-Americana De Enfermagem, 15(1), 27-33. https://doi.org/10.1590/s0104-116920070001000 05

Schweizer, K., Moosbrugger, H., \& Goldhammer, F. (2005). The structure of the relationship between attention and intelligence. Intelligence, 33(6), 589-611. https://doi.org/10.1016/j.intell.2005.07.001

Stinchcombe, A. L. (1971). A heuristic procedure for interpreting factor analyses. American Sociological Review, 36(6), 1080. https://doi.org/10.2307/2093767

Sturm, W. (2009). Aufmerksamkeitsstörungen [Impairments of attention]. In W. Sturm, M. Herrmann, \& T. F. Münte (Eds.), Lehrbuch der klinischen Neuropsychologie: Grundlagen, Methoden, Diagnostik, Therapie (2nd ed., pp. 421-452). Spektrum Akademischer Verlag. 
Talsma, D., Senkowski, D., Soto-Faraco, S., \& Woldorff, M. G. (2010). The multifaceted interplay between attention and multisensory integration. Trends in Cognitive Sciences, 14(9), 400-410. https://doi.org/10.1016/j.tics.2010.06.008

Tams, S., Thatcher, J., Grover, V., \& Pak, R. (2015). Selective attention as a protagonist in contemporary workplace stress: Implications for the interruption age. Anxiety, Stress, and Coping, 28(6), 663-686. https://doi.org/10.1080/10615806.2015.1011141

Verschooren, S., Schindler, S., de Raedt, R., \& Pourtois, G. (2019). Switching attention from internal to external information processing: A review of the literature and empirical support of the resource sharing account. Psychonomic Bulletin \& Review, 26(2), 468-490. https://doi.org/10.3758/ s13423-019-01568-y

Weyer, G., Hodapp, V., \& Neuhäuser, S. (2014). Subjektive Zufriedenheit und Belastung von Arbeit und Beruf [Subjective Satisfaction and Strain by Work and Occupation]. https://doi.org/10.6102/ZIS3

Worthington, R. L., \& Whittaker, T. A. (2006). Scale Development Research. The Counseling Psychologist, 34(6), 806-838. https://doi.org/10.1177/0011000006288127 